Trab. Ling. Aplic., Campinas, (43): 115-126, Jan./Jun. 2004

\title{
DO MÉTODO À AUTONOMIA DO FAZER CRÍTICO
}

\author{
ROSANA E. MENEGAZZO \\ (Pós-graduação em Educação - UFSC) \\ ROSELY PEREZ XAVIER \\ (Universidade Federal de Santa Catarina)
}

\begin{abstract}
This article revisits the notion of method and tracks the second/foreign language teaching based on the application of methods. It also brings the postmethod condition up which redefines the relation between theorizers and practitioners (Kumaravadivelu, 1994), and emphasizes the need for the teachers to reflect on the principles and conceptions that underlie their pedagogical and methodological decisions, so that they can generate their own knowledge, change attitudes, improve their teaching and get better learning results. Reflective thinking is therefore seen as a step towards autonomy that requires the teachers' involvement with their own teaching, the school they work, and the students they teach.
\end{abstract}

Keywords: method, second/foreign language teaching, reflective teaching.

\section{O MÉTODO}

A noção de método e a sua história no ensino de línguas estrangeiras são brevemente resgatadas neste artigo com o objetivo de problematizar o termo e sugerir uma visão mais autônoma, reflexiva, construtiva e transformadora de ensino através do entendimento do professor sobre o seu fazer pedagógico.

Por muitos anos, as escolas de línguas valeram-se do 'método' como elemento diferenciador entre elas. Em cursos de graduação em Letras, por outro lado, o estudo dos diversos métodos de ensino foi e, em alguns casos, ainda é realizado em disciplinas pedagógicas como Metodologia de Ensino e Prática de Ensino de Língua.

Anthony (1972) define método como "um plano geral para a apresentação ordenada do material lingüístico, sendo que nenhuma parte deve se contradizer, e todo o plano deve basear-se numa abordagem selecionada"1 (p.6). Da mesma forma, Allwright (1997) conceitua método como uma descrição geral, derivada de uma teoria de ensino e aprendizagem de línguas para todas as decisões de procedimentos que um professor necessita tomar. Para Els et al. (1984), método refere-se à especificação de objetivos, à seleção de conteúdos e de procedimentos didáticos, ou seja, é um conjunto coerente de todas as considerações que dizem respeito ao que é ensinado e como é ensinado.

1 "Method is an overall plan for the orderly presentation of language material, no part of which contradicts, and all of which is based upon, the selected approach". 
Ao comparar essas definiç̧ões, conclui-se que método é basicamente um conjunto ordenado, estável e coerente de procedimentos, atividades e técnicas de ensino, utilizados pelos professores para desenvolver o conteúdo programático. Deriva ainda de teorias e modelos de aquisição de segunda língua (L2) ou de língua estrangeira (LE). Por essa razão, é possível dizer que método é a aplicação de princípios teóricos (WAGNER, 1991). O Método Audiolingual, por exemplo, baseia-se no estruturalismo ${ }^{2}$ e na teoria behaviorista da aprendizagem ${ }^{3}$. O Natural Approach, por outro lado, fundamenta-se na teoria de aquisição de Krashen (1981) que se constitui em cinco hipóteses: a distinção entre aquisição e aprendizagem; a ordem natural de aquisição; o papel do monitor; o papel do insumo e a hipótese do filtro afetivo. Segundo Krashen, as condições essenciais para adquirir uma L2/ LE são: a exposição do aluno ao insumo ótimo (optimal input), isto é, a um insumo compreensível, interessante e/ou relevante, não seqüenciado gramaticalmente e suficiente em quantidade, e a construção de um ambiente afetivo favorável para os alunos (i.e. com baixa ansiedade, alta motivação, boa auto-estima e auto-confiança), o que permite a assimilação do insumo compreensível. Já os métodos Silencioso, Resposta Física Total, Sugestopedia e Aprendizagem de Língua em Comunidade basearam-se em teorias de interação social ao invés de teorias linguiísticas (WAGNER, 1991).

Para Richards \& Rodgers (1993), o método é a operacionalização da teoria que, por sua vez, determina o fazer docente. Por estarem atrelados às teorias, os métodos apresentam poder normativo, com técnicas padronizadas de ensino a serem seguidas pelo professor. Dessa forma, a prática pedagógica limita-se aos procedimentos prescritos pelo método, ou seja, significa ser fiel a ele. Livros como Approaches and Methods in Language Teaching ${ }^{4}$ e Techniques and Principles in Language Teaching são famosos por trazerem as características de cada método e seus procedimentos de aula.

Algumas escolas de línguas utilizam ainda a noção de método para padronizar a prática pedagógica dos professores. Daí os cursos de treinamento que estabelecem o que vai ser ensinado e geralmente como, muitas vezes com base no livro didático adotado. Se, por um lado, é possível afirmar que o método prescreve receitas pedagógicas, inibindo a autonomia didática do professor e, por conseguinte, seu autoconhecimento como profissional, por outro, ele atrai professores que acreditam nessas receitas como solução de problemas que ocorrem em sala de aula. O método, portanto, parece dar uma sensação de conforto e segurança para certos professores. É o que sugerem as falas a seguir, de entrevistas realizadas com professores de escolas de línguas sobre ser professor de inglês e o seu fazer docente (MENEGAZZO, 2003).

${ }^{2}$ Estruturalismo é uma teoria da linguagem que concentra-se na análise de características estruturais da língua, especialmente no estudo de relações sincrônicas entre elementos lingüísticos (JARY \& JARY, 1991, p. 633).

${ }^{3}$ A teoria behaviorista, advinda da psicologia, determina que a criança aprende uma língua através do processo de condicionamento. A sua produção verbal é formada pelo reforço dos sons de sua língua nativa (JARY \& JARY, 1991, p. 38-39).

${ }^{4}$ RICHARDS, J.C. \& RODGERS, T.S. Cambridge: CUP, 1986, 1993.

${ }^{5}$ LARSEN-FREEMAN, D. Oxford: OUP, 1986. 
Eu acho que tem que ter um treinamento na parte... até de, hum, do método da escola, para que a pessoa não fuja do que aprendeu no treinamento... porque senão o método não vai funcionar e os alunos não vão aprender. (P-EI4)

...acho que treinamento... para que o professor se sinta seguro na sala de aula, né?, e não... não seja pego de surpresa pelos alunos, que esteja despreparado, né? Então, se o professor segue o método, não vai acontecer esse tipo de coisa... (P-EI4)

Essa 'falsa' sensação de conforto e segurança que o método pode trazer limita a sala de aula a um contexto estático, sob total e exclusivo controle do professor (ALLWRIGHT, 1997). Ao contrário, a sala de aula é um evento social (PRABHU, 1992), ou seja, um contexto dinâmico, mutável e complexo que exige do professor conhecimento, habilidade e autonomia para tomar suas decisões conforme as características do grupo. Ao produzir conhecimento através de sua prática, o professor desenvolve uma alternativa sistemática, coerente e relevante para o método.

\section{DA ASCENSÃO À PSEUDODERROCADA DA NOÇÃO DE MÉTODO}

Nos primórdios da história da humanidade, a aprendizagem de uma LE/L2 baseavase no que hoje é chamado de método natural, ou seja, na aprendizagem desprovida de um formalismo ou de um sistema de ensino. Ela acontecia predominantemente via oral, isto é, pelo contato com outras pessoas, pela observação e imitação. A partir do século XV, com o aperfeiçoamento da imprensa e a crescente difusão de obras greco-romanas, surgiu a necessidade do ensino do grego e, principalmente, do latim. O processo de ensino que anteriormente era baseado na oralidade passou a ser desenvolvido através da leitura de textos de forma metódica, enfatizando a tradução e a memorização de regras gramaticais e de vocabulário. Posteriormente, mesmo com o latim sendo relegado ao segundo plano e a necessidade do ensino de línguas modernas, que passaram a ser dominantes, o processo de ensino continuou basicamente o mesmo (CHAGAS, 1979).

Nos séculos XVI e XVII alguns estudiosos destacaram-se pela busca de novos métodos de ensinar uma LE/L2, dentre eles Montaigne, Comenius e Rousseau. Montaigne buscava, além de um método mais natural de ensino de línguas, a formação de juízos e raciocínios nos alunos. Comenius, um dos grandes precussores da educação moderna e autor da Didática Magna, defendia, ao invés do ensino por meio de regras, um ensino através da experiência direta dos alunos com seus sentidos (audição, tato, visão, paladar). Em outras palavras, através do contato com objetos reais, os alunos "aprendiam fazendo" (learn by doing) 6 . Já Rousseau considerava a criança o centro do processo de ensino e aprendizagem, o que reorientou todos os princípios educacionais, inclusive os de ensino de LE/L2 (CHAGAS, 1979).

No século XIX, destacou-se o Método Clássico, também conhecido como Método Gramática e Tradução, e que ainda sobrevive em algumas práticas pedagógicas atuais,

\footnotetext{
${ }^{6}$ Muitos princípios e idéias de Comenius fundamentaram as atividades e técnicas adotadas posteriormente por diferentes métodos, como jogos e role plays.
} 
devido possivelmente à praticidade de ensinar regras, à facilidade de mensurar o conteúdo lingǘśtico e ao reflexo do processo de ensino e aprendizagem que o professor foi submetido durante o seu curso de graduação em Letras, além da oferta contínua de livros didáticos no mercado com foco camuflado ou não na forma gramatical.

No século XX, vários métodos surgiram para 'reformar'o ensino de LEs, como é o caso do Método Serial de Gouin e do Método Direto. O método Audiolingual, já mencionado anteriormente, teve suas raízes teóricas advindas do Método Direto (RICHARDS \& RODGERS, 1993), que enfatizava a habilidade de expressão oral através do automatismo de formas e estruturas da LE/L2, conduzido por modelos orais e intensa prática. O Audiolingualismo teve o seu apogeu após a Segunda Guerra Mundial, explicado pela necessidade dos soldados adquirirem fluência oral tanto nas línguas de seus aliados quanto nas de seus inimigos. A popularidade deste método ainda perdura em práticas de professores, quando estes propõem a repetição oral sistemática de vocabulário e sentenças-modelo, por exemplo.

Nas décadas de 60 e 70 do século passado, outros métodos alternativos, já mencionados anteriormente, foram introduzidos no ensino de LE/L2 como o Silencioso, Resposta Física Total, Sugestopedia e Aprendizagem de Língua em Comunidade. O método Silencioso apoia-se na premissa de que o silêncio, em oposição à repetição, auxilia os alunos na concentração e organização mental do conteúdo. A repetição, por outro lado, consome tempo e dispersa a atenção dos alunos. Neste método, os recursos visuais como bastões coloridos de madeira e cartazes com a pronúncia ou vocábulos codificados por cores servem de mediadores associativos que facilitam a memorização e retenção. A LE/L2 é praticada por meio de situações que requerem a construção de sentenças com o vocabulário codificado.

O ensino de uma LE/L2 através de respostas físicas (motoras) é o que caracteriza o Método Resposta Física Total. O movimento físico da criança é a resposta para o estímulo verbal do professor. Este método desenvolve inicialmente a compreensão oral na LE/L2 para, posteriormente, desenvolver a expressão oral dos alunos. A Sugestopedia, por sua vez, baseia-se na concepção de que o cérebro humano processa grandes quantidades de informação se exposto a ótimas condições de aprendizagem. O fundo musical e o relaxamento são técnicas utilizadas para o aluno chegar a um estado mental relaxado, sem ansiedade e tensão, de modo a deixar sua mente aberta para o conteúdo de ensino, facilitando a memorização e a lembrança (recall). Na Aprendizagem de Língua em Comunidade, professor e alunos assumem papéis de conselheiro (counselor) e cliente, respectivamente, visando gerar uma interação harmoniosa entre eles e, assim, facilitar a aprendizagem. Este método fundamenta-se numa visão holística de aprendizagem de línguas, num processo que envolve aspectos cognitivos e afetivos.

Diante da existência de tantos métodos e do seu papel central no processo de ensino e aprendizagem no final dos anos 60 , pesquisas foram conduzidas para comparar e buscar o 'melhor método'. É o caso do Projeto Pensilvânia cujo objetivo foi comparar o método Audiolingual e o Cognitivo. Allwright (1997) relata que os resultados da pesquisa mostraram-se inconclusivos devido a outros elementos do processo de ensino e aprendizagem que concorrem para o sucesso de um curso, dentre eles o professor. Deste modo, as pesquisas tomaram uma nova direção e passaram a considerar o professor uma variável importante para o sucesso de um curso, ou ainda, para o processo de aprendizagem 
de LE/L2. Seus papéis começaram a ser analisados em pesquisas baseadas na análise da conversação e na etnometodologia ${ }^{7}$. Pesquisadores, entretanto, começaram a questionar a validade de se considerar apenas o professor como fator de influência para o sucesso de um curso, uma vez que professor $e$ alunos são co-produtores (gerenciadores) do processo de ensino e aprendizagem, buscando trabalhar coletivamente na criação e enriquecimento de oportunidades de aprendizagem (ALLWRIGHT, 1991a,b).

Prabhu (1990) salienta que a procura do melhor método é algo utópico, pois o sucesso de um curso depende de uma série de fatores ou variáveis que influenciam na aprendizagem do aluno. Essas variáveis podem estar relacionadas ao próprio aluno (ex. suas aspirações, personalidade, estilo de aprendizagem), ao professor (ex. sua motivação, habilidade, atitude frente à língua que ensina) e à organização educacional (ex. objetivos da escola, carga horária, recursos).

Para Pennycook (1989), o conceito de método é questionável devido à sua imprecisão e à carga ideológica que carrega. $\mathrm{O}$ autor observa que as técnicas, atividades e procedimentos específicos de um método não são exclusivos dele. É o caso do uso de diálogos, brincadeiras e role plays que podem reocorrer em vários métodos. Segundo Kelly (1976), há uma certa alternância ou mudança cíclica nos princípios e procedimentos metodológicos de um método para outro e, com o passar do tempo, muitos dos procedimentos metodológicos são abandonados em favor de outros na tentativa de desenvolver o 'melhor método' ou a melhor maneira de se ensinar uma LE/L2. Essas mudanças são, para Pennycook (1989), decorrentes do contexto social, cultural, político e filosófico de uma época. Esta visão historicista de método, como processo cíclico de mudanças procedimentais, difere da visão positivista e progressista de Titone (1986, apud PENNYCOOK, 1989) que sustenta a noção de método como um processo linear de desenvolvimento ao longo do tempo, o que significa dizer que o ensino de LE/L2 tem sido legitimado por princípios científicos.

Outro aspecto salientado por Pennycook (1989) refere-se à manutenção da visão positivista de método, a qual beneficia as políticas econômicas de publicação de livros didáticos. Em outras palavras, os benefícios comerciais dos editores derivam dos métodos que estão em evidência no momento, geralmente promovidos e patrocinados por membros de universidades ou instituições de renome que, por razões políticas, econômicas e ideológicas, investem na manutenção do conceito de 'método'. Allwright (1997) compartilha da mesma opinião e salienta que os editores rapidamente perceberam o potencial comercial do 'método'. Há ainda a questão da exportação de métodos 'avançados' de países desenvolvidos para os subdesenvolvidos, onde profissionais da área adotam estes métodos como diretrizes a seguir, desconsiderando o próprio contexto social e cultural em que estão inseridos (PENNYCOOK, 1989).

No Brasil, o interesse pela conservação da noção de método estende-se às escolas de línguas, que se valem deste estratagema para se diferenciarem umas das outras e competirem no mercado, enfatizando a superioridade do seu método. Além disso, a adoção de um

\footnotetext{
${ }^{7}$ Etnometodologia é um ramo da sociologia que estuda as relações entre as pessoas e a maneira como a interação social acontece entre elas. A língua não é o principal interesse para os etnometodólogos, mas a observação de como ela é usada nas atividades diárias como, por exemplo, na interação entre criança e adulto, numa entrevista, ou ainda, numa conversa ao telefone. (RICHARDS et al, 1985).
} 
método facilita a padronização do ensino e o seu controle, além de oportunizar a sua disseminação em franquias. As escolas de línguas ‘controlam’ a metodologia de ensino do professor através de cursos de treinamento que objetivam prepará-lo para seguir os princípios metodológicos estabelecidos pela escola.

Três razões explicam a noção inconsistente e esvaziada do termo método. A primeira refere-se à falta de consenso quanto ao número de métodos que existiram, seu período de vigência e sua ordem de ocorrência (PENNYCOOK, 1989, ELS et al., 1984). Brown (1980, 1987), por exemplo, considera ter havido um novo paradigma a cada 25 anos, conservandose, a cada novo paradigma, os pontos positivos do anterior. A respeito de quais e quantos métodos existiram, Brown (op.cit.) declara a existência dos seguintes métodos: Direto, Gramática e Tradução, Audiolingual e Abordagens Interpessoais que incluem os "novos métodos": Silencioso, Resposta Física Total, Sugestopedia e Aprendizagem de Língua em Comunidade. Clark (1982, apud PENNYCOOK, 1989), por outro lado, sugere terem existido quatro métodos: Gramática e Tradução, Estrutural/ Audiolingual, Interacional/ Humanístico e Nocional/Funcional. Richards \& Rodgers (1993), por sua vez, propõem oito. Quanto à seqüência de ocorrência dos métodos, Brown $(1980,1987)$ altera a ordem proposta por Richard \& Rodgers, colocando o Método Gramática e Tradução após o Método Direto.

A segunda questão sobre a inconsistência do termo método, apontada por Pennycook (1989), está na falta de coerência conceitual quando usado por lingüistas aplicados, educadores e professores. Anthony (1972) faz uma distinção entre abordagem, método e técnica, ao passo que Richards \& Rodgers (1993) colocam abordagem, design e procedimento como subcategorias do termo método. Richards \& Rodgers (op.cit.) consideram o Ensino Comunicativo de Língua uma abordagem ao invés de um método, já que o design e os procedimentos podem ser interpretados de várias maneiras. Brown, por sua vez, considera o método Audiolingual uma abordagem, uma vez que há muitas variações de tal método (PENNYCOOK, 1989).

A terceira razão que explica a noção inconsistente e esvaziada do termo método reside na pouca evidência sobre se a predominância de um método, num determinado período, era resultante do que realmente acontecia nas salas de aula. Mesmo porque os estudos envolvendo observações de aula sugerem uma discordância entre o que os professores dizem estar fazendo, o que os pesquisadores relatam sobre o que os professores estão fazendo e o que realmente ocorre em sala de aula (PENNYCOOK, 1989). Da mesma forma, Wagner (1991) questiona se realmente houve uma relação de causa e efeito entre teoria e prática de ensino. Pesquisas empíricas revelam que o professor não segue um método em particular, mas diferentes técnicas, atividades e procedimentos de métodos diversos (ecletismo).

Diante de tantas críticas ao conceito de método, muitos autores tentam redefini-lo. É o caso de Prabhu (1990) que define o termo como um conjunto de atividades a serem realizadas em sala de aula e a teoria, crença ou conceito plausível que norteiam tais atividades. Nota-se aqui uma aproximação entre as ações pedagógicas e os princípios que as regem. Este conceito possibilita ao professor a produção de seu próprio conhecimento a partir de sua prática. Wagner (1991), por outro lado, desmembra o termo em: Método e Métodos. Métodos são padrões bem definidos de técnicas de ensino. Já Método refere-se 
ao que realmente acontece na sala de aula. Essas tentativas de redefinição de método visam propor uma noção descritiva ao invés de prescritiva das ações pedagógicas.

\section{A VISÃO PÓS-MÉTODO}

A visão pós-método (KUMARAVADIVELU,1994) é marcada por questionamentos quanto ao termo e conceito de método (já discutidos acima), à dependência/obediência a ele e ao ecletismo.

A noção de método coloca os teóricos na posição de produtores de conhecimento, assumindo um papel central no desenvolvimento de teorias de ensino e aprendizagem, enquanto que os professores se colocam como consumidores ou aplicadores deste conhecimento, cabendo a eles uma certa dependência/obediência ao método. Na visão pós-método, no entanto, o professor é considerado capaz de teorizar sua própria prática a partir do contexto em que está inserido, produzindo, dessa forma, seus próprios conhecimentos. A condição pós-método reconhece o potencial do professor de saber não somente como ensinar, mas também como agir autonomamente e conduzir uma análise crítica de suas ações em sala de aula.

O ecletismo, que é vinculado ao conceito tradicional de método, consiste em combinar as melhores partes de cada método sem, necessariamente, a consonância entre os critérios escolhidos, ou ainda, sem fundamentar-se em princípios teórico-metodológicos compatíveis, para, desse modo, construir um novo método. Na visão pós-método, o ecletismo é criticado por gerar uma prática pedagógica "assistemática, sem princípios e acrítica" (KUMARAVADIVELU,1994). Dá-se lugar, então, ao 'pragmatismo com princípios' (principled pragmatism), que se baseia na pragmática da pedagogia (WIDDOWSON, 1990), a qual valoriza as atividades de ensino moldadas e geridas pelo professor através de sua postura engajada, reflexiva e crítica. Segundo Kumaravadivelu (op. cit.), uma das maneiras de o professor desenvolver o pragmatismo com princípios é fortalecer o seu senso de plausibilidade ${ }^{8}$.

Assim como Kumaravadivelu considera o pragmatismo com princípios uma alternativa para o método, Allwright (1991a, 1997) vê como perspectiva a criação de um elo entre ensino e pesquisa, principalmente entre professores e pesquisadores através de uma 'prática exploratória'. Esta prática visa desenvolver uma compreensão do que acontece na sala de aula, buscando não somente contribuir para o entendimento do ensino e aprendizagem, mas também para o aumento das chances dos alunos fazerem progresso. $\mathrm{O}$ autor compartilha com Prabhu (1987, 1990, 1992) a necessidade de o professor articular seus próprios princípios de ensino e aprendizagem para dar sentido à sua prática e fortalecer o seu 'senso interno de coerência', o que significa o seu 'senso de plausibilidade'.

${ }^{8}$ Senso de plausibilidade é o entendimento subjetivo que o professor tem do seu próprio ensino. Esse entendimento decorre dos conceitos de ensinar e aprender construídos pelo professor ao longo de sua visa acadêmica e profissional, mais precisamente a partir de sua experiência enquanto aluno e professor, de experiências de ensino compartilhadas entre colegas, dos conhecimentos adquiridos em seu curso de formação inicial e/ou continuada, entre outros. (PRABHU, 1987, 1990) 
Nessa mesma perspectiva, Allan (1997) e Nunan (1997) sugerem a 'pesquisa na ação', a qual busca colocar o professor no centro do processo de pesquisa, ajudá-lo a solucionar problemas diagnosticados em situações específicas do próprio contexto, a desenvolver ainda mais suas habilidades e autoconhecimento, e a melhorar sua comunicação com os pesquisadores acadêmicos. Nota-se aqui uma proposta de parceria entre professores e pesquisadores acadêmicos para o crescimento profissional conjunto.

Em suma, a visão pós-método possibilita ao professor sair da letargia e o convida a produzir conhecimentos a partir de sua prática, mediante constante análise e avaliação do seu processo de ensinar e do processo de aprender que ele gera. Ao tomar conhecimento do que ocorre em sala de aula e ao refletir criticamente sobre sua prática, o professor busca melhorar a qualidade de seu ensino e da aprendizagem de seus alunos.

\section{A AUTONOMIA DO FAZER CRÍTICO}

Diante da condição pós-método, que coloca o professor na posição de investigador de sua prática e na de um profissional autônomo ${ }^{9}$, consciente e articulador de mudanças, $\mathrm{o}$ professor necessita refletir mais profundamente sobre suas ações e decisões pedagógicas. Seu foco de reflexão pode estar nos objetivos de ensino (ex. Que objetivos você estabelece para cada série, estágio ou curso? Eles atendem às necessidades dos alunos? Por que acha isso? São relevantes para a vida deles? Em que sentido? O que visam desenvolver?), no conteúdo instrucional (ex. Que tipo de conteúdo você propõe ensinar? Qual é a relação deste conteúdo com a vida dos alunos? Contribui para torná-los cidadãos críticos e participativos na sociedade? Como?); na interação com os alunos (ex. Compartilha com os alunos o gerenciamento de sala de aula e as decisões pedagógicas? Como você faz isso? Ignora situações constrangedoras como certos tipos de indisciplina, brigas entre alunos? O que você faz nestes momentos? Por que faz assim?), na visão de si mesmo, como profissional, e de seus alunos (ex. Você costuma subestimar a capacidade dos alunos ao facilitar as respostas, ao evitar falar na LE? Você acredita no potencial deles? Acredita em você? Acredita que pode mudar? Gostaria de mudar? Por que sim/ não? Por onde você começaria?), na avaliação (ex. Você diagnostica as dificuldades da classe? Como faz isso? Como trata as dificuldades encontradas? O que você faz com aqueles alunos que apresentam sérias dificuldades de aprendizagem?) e nas atividades escolhidas ou elaboradas (ex. Que formas de raciocínio você contempla? Que habilidades lingüísticas você prioriza? Por que?) (XAVIER, 2002).

Além de se descobrir como profissional, o professor, na busca pela transformação do seu fazer, muitas vezes precisa saber como mudar, vivenciar experiências diferentes das cotidianas, ter um parceiro que possa observá-lo e fazer comentários construtivos, além de saber lidar com certas limitações e/ou falta de estímulos oriundas de seu próprio ambiente de trabalho.

\footnotetext{
${ }^{9}$ Neste estudo, profissional autônomo é aquele que possui "consciência crítica dos interesses e valores e do conhecimento das capacidades e aptidões próprias, dentro de princípios de liberdade, responsabilidade e solidariedade" (CARDOSO et al, 1996, p. 72)
} 
A autonomia do professor pode estar relacionada às suas atitudes, decisões e postura frente aos valores ideológicos dominantes que limitam as possibilidades da ação docente (BORGES, 2002). Por exemplo, o professor pode seguir o conteúdo do livro didático sem questioná-lo; pode ainda adaptá-lo, complementá-lo com atividades mais significativas. Pode, ao contrário, elaborar o seu próprio material de ensino a partir de compilações ou, então, a partir de sua criatividade. O grau de autonomia do professor vai depender da margem de ação que lhe é concedida no ambiente de trabalho. Cabe a ele aproveitar esta margem de autonomia, com muita responsabilidade e visão emancipatória da profissionalização docente, pois "é na ação refletida e na redimensão de sua prática que o professor pode ser agente de mudanças na escola e na sociedade" (LIMA \& GOMES, 2002, p.169).

A emancipação do trabalho docente é um objetivo histórico, condição para o seu próprio desenvolvimento profissional e pessoal. Essa emancipação é, em parte, conquistada individualmente, quando o professor adota uma postura crítica em relação ao seu próprio ensino, isto é, às suas escolhas e ações pedagógicas em sala de aula. É também conquistada coletivamente na medida em que os professores têm a chance de, em conjunto, elaborar propostas pedagógicas, projetos de trabalho, documentos normatizadores, dentre outras tarefas compartilhadas. Agindo individualmente, o professor pode reagir frente às situações que restringem sua prática pedagógica. Coletivamente, os professores passam a se conhecer melhor e a procurar juntos maneiras de superar os entraves encontrados no caminho do processo de ensino e aprendizagem.

É importante destacar que a iniciativa de mudança no âmbito escolar depende em grande parte dos professores. Ao observar, analisar, questionar, reinterpretar, testar, avaliar sua prática pedagógica, o professor caminha para uma transformação do seu fazer docente. Em seu ambiente de trabalho, o professor de inglês, por exemplo, pode redimensionar a importância de sua disciplina ao contribuir para a formação de cidadãos participativos e críticos. Certamente, isso não se conquista através de um ensino voltado para a forma gramatical ou para um conjunto de funções comunicativas, ou ainda, de um ensino distante da realidade dos alunos. O professor de inglês pode causar impacto na comunidade ou na visão de mundo dos alunos, na medida em que seu ensino propõe projetos de trabalho e atividades com a participação dos alunos nas tomadas de decisão, na solução de problemas ou nas situações postas do dia-a-dia, promovendo, desse modo, diversas formas de pensar, agir e transformar o contexto em que se encontram. Como afirma Libâneo (2002),

[e]ducar, diante deste horizonte, é ter a coragem de romper consigo mesmo para poder instaurar uma nova compreensão da ação e dela imprimir uma nova ação reflexiva, tornando possível a ampliação do poder de autodeterminação. Somente desta maneira poderemos possibilitar a construção da cidadania responsável, tornando possível a democracia participativa e a negação da democracia deliberativa. (p. 66)

Para que as mudanças possam ser significativas, é preciso que o professor aprenda a partilhar saberes, a pensar com a escola e não somente sobre a escola, a compreender a reflexão como prática social que oportuniza o apoio e o estímulo mútuos, a trabalhar coletivamente, a analisar os contextos de ensino e aprendizagem, a qualificar melhor os 
discursos oficiais que geralmente se valem de termos ou conceitos da moda, buscando resignificá-los (LIMA \& GOMES, 2002). Giroux (1997), por outro lado, salienta a necessidade de os professores se tornarem intelectuais transformadores, ou seja, questionadores acerca do que e como ensinam e principalmente delineadores de metas pelas quais devem lutar. Em suas palavras, os professores

\begin{abstract}
[p]recisam desenvolver um discurso que una a linguagem da crítica e a linguagem da possibilidade, de forma que os educadores sociais reconheçam que podem promover mudanças. Desta maneira, eles devem se manifestar contra as injustiças econômicas, políticas e sociais dentro e fora das escolas. Ao mesmo tempo, eles devem trabalhar para criar as condições que dêem aos estudantes a oportunidade de tornarem-se cidadãos que tenham o conhecimento e coragem para lutar a fim de que o desespero não seja convincente e a esperança seja viável. Apesar de parecer uma tarefa difícil para os educadores, esta é uma luta que vale a pena travar. Proceder de outra maneira é negar aos educadores a chance de assumirem o papel de intelectuais transformadores. (p.163)
\end{abstract}

O compromisso do professor, portanto, não é apenas com o que ocorre em sala de aula, mas também com os elementos condicionantes de sua prática, buscando, assim, modificar o que a limita. Os professores intelectuais transformadores, além de refletirem sobre a sua prática e o seu contexto de trabalho, precisam se comprometer com a formação de cidadãos ativos, críticos e também transformadores.

\title{
5. CONCLUSÃO
}

O processo de entendimento do fazer pedagógico é construído com base nas crenças, princípios, valores e nas teorias implícitas que o professor carrega. Certamente, os saberes e conhecimentos dos professores não permanecem estáticos ao longo do tempo (ou, pelo menos, não deveriam); devem ser reinterpretados continuamente com as experiências adquiridas no cotidiano escolar e fora dele. Em outras palavras, o professor pode melhorar a sua prática pedagógica e, conseqüentemente, a aprendizagem dos alunos, à medida que ele compreende o que faz em sala de aula, questiona suas ações, vivencia com responsabilidade certas experiências diferenciadas, avalia essas novas experiências, acredita nos alunos e em si próprio, deseja mudar verdadeiramente e continuar se desenvolvendo a partir dos conhecimentos construídos na prática reflexiva e em contextos acadêmicos, sem se esquecer, no entanto, de seu papel de gerar mudanças na sociedade. Neste sentido, o professor caminha para uma autonomia ou consciência crítica de suas ações pedagógicas, podendo impactar a sociedade através do seu ensino e da aprendizagem que gera nos aprendizes.

\section{REFERÊNCIAS BIBLIOGRÁFICAS}

ALLAN, D. (mar. 1997). Action research and teacher development. ELT News \& Views Supplement, n. 4. 1, p. 5-7. 
ALLWRIGHT, D. \& BAILEY, K. M. (1991(a)). Focus on the language classroom: an introduction to classroom research for language teachers. Cambridge: Cambridge University.

(1991(b)). The death of the method. Lancaster University, Linguistics and English Language Department: Centre for Research in Language Education. p 1-12.

. (1997). Planning for understanding: a new approach to the problem of method. Lancaster University, Linguistics and English Language Department: Centre for Research in Language Education (CRILE), working Paper no. 9, p. 1-19.

ANTHONY, E. M. (1972). Approach, method and technique. In. ALLEN, Harold B. \& CAMPBELL, Russel N. Teaching English as a second language: a book of readings. $2^{\mathrm{a}}$ ed. New Delhi, India: Tata McGraw-Hill. p. 4-8.

BORGES, R. C. M. B. (2002). O professor reflexivo-crítico como mediador do processo de inter-relação da leitura-escritura. In. PIMENTA, S. G. \& GHEDIN, E. (orgs.) Professor reflexivo no Brasil: gênese e crítica de um conceito. São Paulo: Cortez. p. 201-218.

BROWN, H. D. (1980). Principles of language learning and teaching. Englewood Cliffs, NJ: Prentice Hall Regents.

(1987). Principles of language learning and teaching. $2^{\mathrm{a}}$ ed. Englewood Cliffs, NJ: Prentice Hall Regents.

(1994). Teaching by principles: an interactive approach to language pedagogy. Prentice Hall Regents.

CARDOSO, A. M. (1996). et al. O movimento da autonomia do aluno: repercussões a nível da supervisão. In. ALARCÃO, I. (orgs.) Formação reflexiva de professores: estratégias de supervisão. Porto: Porto. p. 6388.

CHAGAS, V. (1979). Didática especial de línguas modernas. $3^{\mathrm{a}}$ ed. São Paulo: Companhia Editora Nacional.

ELS, T. V. (1984). (et. al). Applied linguistics and the learning and teaching of foreign languages. Baltimore: Edward Arnold.

GIROUX, H. A. (1997). Os professores como intelectuais: rumo a uma pedagogia crítica da aprendizagem. Porto Alegre: Artes Médicas.

JARY, D. \& JARY, J. (1991). Dictionary of sociology. Great Britain: HarperCollins.

KELLY, L. G (1976). 25 centuries of language teaching: 500 BC - 1969. Massachusetts: Newbury House.

KRASHEN, S. (1981). Second language acquisition and second language learning. Oxford: Pergamon.

KUMARAVADIVELU. B. (1994). The postmethod condition: (e)merging strategies for second/foreign language teaching. Tesol Quarterly, vol. 28, no. 1, p. 27-48.

LARSEN-FREEMAN, Diane. (1986). Techniques and principles in language teaching. Oxford: Oxford University Press.

LIBÂNEO, J. C. (2002). Reflexividade e formação de professores: outra oscilação do pensamento pedagógico brasileiro? In. PIMENTA, S. G. \& GHEDIN, E. (orgs.) Professor reflexivo no Brasil: gênese e crítica de um conceito. São Paulo: Cortez. p. 53-79.

LIMA, M. S. L. \& GOMES, M. O. (2002). Redimensionando o papel dos profissionais da educação: algumas considerações. In. PIMENTA, S. G. \& GHEDIN, E. (org.) Professor reflexivo no Brasil: gênese e crítica de um conceito. São Paulo: Cortez. p. 163-186. 
MENEGAZZO \& XAVIER - Do método à autonomia...

MENEGAZZO, R. E. (2003). Concepções sobre ser professor de inglês e o seu fazer docente. Florianópolis. 147p. Dissertação (Mestrado em Educação) - Curso de Pós-Graduação em Educação, Universidade Federal de Santa Catarina.

NUNAN, D. (1997). Teaching portfolios for teacher development.. ELT News \&Views Supplement, no. 4.1, p.4-7, mar.

PENNYCOOK, A. (dez. 1989). The concept of method, interest knowlegde, and the politics of language teaching. Tesol Quarterly: vol. 23, no 4, p. 589-618.

PRABHU, N. S. (1987). Second language pedagogy. Oxford. (1990). There is no best method - why? Tesol Quarterly: vol. 24, no 2, p.161-176. (1992). The dynamics of the language lesson. Tesol Quarterly, vol. 26, no. 2, p.225 -241.

RICHARDS, J. C. (1985). et al. Longman dictionary of applied linguistics, Harlow: Longman.

RICHARDS, J. C. \& RODGERS, T. S. (1993). Approaches and Methods in Language Teaching: a description and analysis. $9^{\mathrm{a}}$ ed. Cambridge: Cambridge University.

WAGNER, J. (1991). InnovForeign/second language pedagogy research. Clevedon: Multilingual Matters Ltd. p.287-306.

WIDDOWSON, H. G. (1990). Aspects of language teaching. Oxford: Oxford University Press. (1983). Learning purpose and language use. Oxford: Oxford University Press.

XAVIER, R. P. Reflexões sobre o fazer pedagógico: Em busca da compreensão e consciência crítica. In Anais do II Fórum Internacional de Ensino de Línguas Estrangeiras, Pelotas, RS. 